\title{
Para uma história das histórias do cinema português
}

Paulo Cunha ${ }^{1}$

Durante décadas, a história do cinema português não foi feita por historiadores ou académicos das ciências sociais e humanas, mas por curiosos, entusiastas e autores que estavam comprometidos com o próprio objeto. Mais do que estudar e analisar o cinema português, a produção pseudo-historiográfica produzida até meados da década de 1990 preocupava-se sobretudo por promovê-lo junto do público e da crítica. Foi, portanto, com alguma naturalidade que esses primeiros escritos, apesar de uma importância fundamental na recolha e inventariações das fontes, promovessem a criação de mitos que, de forma mais implícita ou explícita, manipulavam o passado do cinema português e condicionaram a sua construção histórica.

Um bom exemplo é o caso do célebre suposto "ano zero" do cinema português: o ano de 1955 é considerado por muitos autores como um "ano zero" uma vez que durante o mesmo não estreou nas salas portuguesas nenhum filme de longa-metragem de produção nacional. Mas, mesmo considerando apenas os filmes, esses autores também desvalorizam os 99 filmes de produção portuguesa com metragem inferior a 1.000 metros de película ou com menos de 60 minutos de duração, segundo dados recolhidos por José de MatosCruz (1989, 112-114). Esses 99 filmes não são considerados como significativos para quem defende a teoria do "ano zero" porque, para a generalidade dos autores, a produção cinematográfica parece limitar-se aos filmes de longa-metragem ou, como na época eram mais populares, os filmes de fundo. Mas, como a história do cinema não se faz só com os filmes, 1955 é sobretudo um ano de intensa atividade para o movimento cineclubista e para a crítica cinematográfica portuguesa, dois núcleos de pensamento e ação que se opunham ao modelo estatal de política cultural e que estariam na génese de uma mudança de paradigma que se materializaria no início dos anos 60 .

O principal responsável pela estrutura narrativa dominante acerca do primeiro cinquentenário do cinema português foi Manuel Félix Ribeiro, alto funcionário do departamento da Propaganda do Estado Novo (SPN/SNI/SEIT) desde 1935 e primeiro diretor da Cinemateca Portuguesa (1948-1983), que, qual Heródoto, "viveu quase tudo o que relata" e "assistiu pessoalmente à criação de factos descritos ou guardou memórias recentes" (Luís de Pina cit. in Ribeiro 1983, V). Apesar de bem-intencionada, esta afirmação é falaciosa, porque

\footnotetext{
${ }^{1}$ Universidade de Coimbra, Centro de Estudos Interdisciplinares do Século XX, 3000-186 Coimbra, Portugal.
} 
induz facilmente o leitor ao erro. Nascido em 1906, Félix Ribeiro só começou a ser testemunha no início dos anos 20, quando o cinema já contava 25 anos de existência. Por outro lado, nos restantes 25 anos, Félix Ribeiro não foi uma mera testemunha, mas sobretudo um dos protagonistas: uma "figura saliente da geração que lançou o cinema português no rumo certo" (Ibidem). Foi pioneiro do jornalismo cinematográfico português, trabalhou em produção e, desde que AntóAntónio Ferro o tornou chefe da Secção de Cinema do recém-criado Secretariado de Propaganda Nacional, "Todo o cinema português passa de algum modo pelas mãos de Félix Ribeiro" (Ibidem).

Seria o primeiro proto-historiador do cinema português ao escrever o primeiro esboço de uma história do cinema português, uma pequena separata intitulada "Panorama histórico do Cinema Português", datada de 1946, que percorre, ao longo de 44 páginas, o percurso do cinema português desde Aurélio da Paz dos Reis (1896) até 1944. Considerada pelo próprio autor como a "primeira história do cinema nacional", esta separata do Anuário Cinematográfico Português (Edições Gama, 1946) enuncia os principais factos do cinema português de uma forma cronológica e aparentemente descritiva.

Em 1949 é um dos autores da primeira tentativa conhecida de esboçar uma história do cinema português, o projeto A Maravilhosa História da Arte das Imagens, obra em que escreve os capítulos referentes ao caso português: «O advento da produção cinematográfica em Portugal», «O Porto na vanguarda da produção nacional», estes em coautoria com Fernando Fragoso, e «Cinema português feito por portugueses», a solo. Coordenada por Fernando Fragoso e Raul Faria da Fonseca, esta obra foi editada em fascículos entre 1949 e 1956, constituindo um esforço conjunto de diversos autores em divulgar alguns dados sobre a nossa cinematografia, não deixando de revelar pouca exigência na análise e problematização dos dados avançados.

A sua obra mais significativa, publicada postumamente, é também exemplar da sua atividade e estilo historiográficos: Filmes, Figuras e Factos do Cinema Português 1896-1949 (Cinemateca Portuguesa, 1983) constitui o precioso relatório de cerca de sessenta anos de recolha de informação sobre as temáticas a que o próprio título alude, reunindo as fichas técnicas, imagens, impressões da imprensa e estórias de bastidores. Como sublinha a introdução de Luís de Pina, essa obra "ultrapassa o documento histórico para salientar o documento humano".

No entanto, não se pode ignorar que a maioria dos seus escritos foram patrocinados por entidades oficiais e, por isso, a sua análise do cinema português enquadra-se num quadro promovido pelo regime sobre o cinema português que reproduz muito das ideias e projetos de António Ferro. Parece-me inequívoco que Manuel Félix Ribeiro foi o primeiro "cronista cinematográfico oficial do reino", o primeiro cronista especializado em assuntos cinematográficos, o 
primeiro dos historiadores do cinema português que vinculam a sua versão pessoal enquanto versão oficial. Félix Ribeiro conceptualizou uma visão sobre a história do cinema português dos primeiros cinquenta anos que, na sua essência, vigora até hoje na generalidade das principais publicações historiográficas portuguesas sobre o período.

Concretamente, foi Félix Ribeiro quem estabeleceu a visão cíclica do cinema português dos primeiros cinquenta anos que ainda hoje vigora na história oficial, nomeadamente os célebres primeiros e segundos ciclos do Porto e Lisboa. Dessa primeira história, o autor destaca os períodos da Invicta Film, do verismo português e das Produções António Lopes Ribeiro como fases fundamentais para o "progresso do cinema português", assim como a consagração da visão pessimista e negativa sobre as tentativas neorrealistas dos anos 50: "a década de 50 não se apresenta muito significativa do ponto de vista quantitativo como qualitativo" (Ribeiro 1983, 3).

Félix Ribeiro fez parte de uma geração que, à semelhança de muitas outras, se concebeu e consolidou na rutura com o passado, na recusa de um status quo e na reivindicação de uma mudança. Félix Ribeiro fez parte da geração que acompanhou António Ferro no seu projeto de refundação do cinema português, ao lado de outros jovens cinéfilos como António Lopes Ribeiro, Leitão de Barros, Jorge Brum do Canto, ou jornalistas como Domingos Mascarenhas ou Fernando Fragoso.

Se Manuel Félix Ribeiro foi o pioneiro, João Bénard da Costa tem sido o autor mais citado e bibliograficamente mais referido em estudos sobre cinema português. Por mais incrível que pareça, os seus escritos, apesar de serem sobretudo textos de divulgação e de síntese, têm sido repetidamente usados em trabalhos académicos sem qualquer sentido crítico. Ainda que contenham muita informação primária, os escritos de Bénard da Costa são demasiado memorialistas para serem confundidos com um olhar crítico e científico. Aqui fica um bom exemplo: em Março de 1964, num dos primeiros sinais de reconhecimento internacional, Pierre Kast assinava na Cahiers $d u$ Cinéma um texto intitulado Lettre de Lisbonne (Março de 1964, 4142), em que anunciava a "nouvelle vague portugaise" promovida por cinco portugueses "unis comme les doigts de la main" (unidos como os dedos de uma mão). Citando o texto original, Bénard da Costa $(1985,30)$ identifica os "dedos" referindo explicitamente os seus sobrenomes: "Rocha, Lopes, Fonseca e Costa, Cunha Telles e Oliveira". No entanto, no texto original, os cinco "dedos" identificados por Pierre Kast foram Paulo Rocha, Fernando Lopes, José Fonseca e Costa, Manuel Guimarães e António da Cunha Telles. O nome de Oliveira é referido como uma referência para todos os outros, como um "ainé" ("amo"), um "artisan type complet" (artista completo) que "fait tout chez lui, à Porto, tout seul” (faz tudo em casa, no Porto, sozinho). 
Ainda que, seguramente, o acesso à fonte estivesse ao alcance de alguns metros ou de poucos minutos, Bénard da Costa confiou mais na sua memória e não confirmou a sua recordação com a fonte primária. Daí para cá, a passagem foi repetida vezes sem conta sem que alguém questionasse a sua veracidade, apesar do acesso à fonte ser relativamente simples.

Assumidamente mais interessado em divulgar e promover um certo cinema produzido em Portugal depois dos anos 60, Bénard da Costa não teve dificuldade em adotar como sua a narrativa com que Félix Ribeiro cristalizou sobre os primeiros cinquenta anos de cinema em Portugal e que entretanto a própria Cinemateca Portuguesa já assumira em várias publicações oficiais.

Um bom exemplo deste processo de transmissão de uma visão pouco problematizadora do passado é o caso da "comédia à portuguesa” a da sua suposta popularidade. O próprio Bénard da Costa, um dos principais responsáveis pela reprodução do mito, por vezes deixa escapar um desabafo mais ácido:

"Depois, tudo mudou, nessa 'idade do ouro' que a gente hoje imagina ter existido aí entre 1931 e 1954, desde A Severa até a O Cerro dos Enforcados? Quando os filmes portugueses seriam a árvore das patacas, tão amáveis, tão amados? Nada mais falso. [...] Lopes Ribeiro recordou, um dia, na Cinemateca, que, à estreia de O Pátio das Cantigas, alguém gatafunhou nas paredes do Éden, glosando uma das mais célebres réplicas do filme: 'Oh, Evaristo! Já viste pior do que isto?'. E assim sucessivamente para os mais conhecidos dos títulos dos anos 30-40, esses que, hoje, ingenuamente se supõe terem agradado desde sempre e para sempre" (Costa 1996, 21).

Apesar de supostamente ser uma época dourada, os anos 30 e 40 do cinema português são dos menos estudados pela historiografia cinematográfica portuguesa, e essa falta de trabalho nas fontes tem permitido que se reproduza uma narrativa proto-historiográfica pouco rigorosa e geralmente "mal contada".

A pergunta impõe-se com alguma frequência: terá sido ou não esse período uma espécie de "idade do ouro" do cinema português? Não pretendo aqui tecer considerações subjetivas sobre a qualidade dos filmes, apenas me preocuparei com questões quantitativas que possam ajudar a esclarecer, por agora, se esses filmes foram ou não os mais populares da história do cinema português.

Como não existem dados de bilheteira anteriores a 1976, o que proponho é um novo método em função dos dados disponíveis contabilizar o tempo de permanência em sala dos filmes portugueses estreados nos anos 40 - que, não sendo os dados referentes aos espectadores, permitem calcular, por razoável aproximação, o eventual sucesso comercial dos filmes. Pela importância da estreia lisboeta no contexto do campo de exibição cinematográfica portuguesa e pela impossibilidade de coligir dados de todas as salas de cinema no terri- 
tório nacional, a pesquisa cingiu-se às salas lisboetas. Assim, o estudo (Cunha 2010) incidiu sobre as estreias dos filmes portugueses de longa-metragem nas salas lisboetas entre 1 de janeiro de 1940 e 31 de dezembro de 1949, contabilizando apenas as sessões de estreia do filme. Reconheço variáveis, como a lotação das diferentes salas ou os preços dos bilhetes, mas a contabilidade destes dados deve ser encarada como um indicador credível e fiável para este propósito.

$\mathrm{O}$ que os dados seriais resultantes desse levantamento revelam é que os filmes portugueses que permaneceram mais tempo em sala de estreia nos anos 40 terão sido: Capas Negras (1947, Armando de Miranda) com 21 semanas de exibição no Condes; Sol e Toiros (1949, José Buchs) com 17 semanas de exibição no Condes; Fado, história de uma cantadeira (1947, Perdigão Queiroga) com 15 semanas de exibição no Trindade; Amor de Perdição (1943, António Lopes Ribeiro), com 12 semanas de exibição no Trindade; O Leão da Estrela (1947, Arthur Duarte) com 11 semanas de exibição no São Luiz; e Três Espelhos (1947, Ladislao Vajda) com 11 semanas de exibição no Trindade.

Para além de $O$ Leão da Estrela, as restantes comédias à portuguesa não terão convencido o público lisboeta: $O$ Costa do Castelo (1943, Arthur Duarte) permaneceu 9 semanas em exibição no São Luiz, O Pai Tirano (1941, António Lopes Ribeiro) foi exibido durante 7 semanas no Éden, A Vizinha do Lado (1945, António Lopes Ribeiro) foi exibido durante 7 semanas no Trindade e O Pátio das Cantigas (1942, Francisco Ribeiro) apenas 4 semanas no Éden. Ironicamente, o épico Camões (1946, Leitão de Barros), o filme mais caro de sempre da história do cinema português, que beneficiou igualmente de uma enorme campanha de promoção, permaneceu apenas 8 semanas em exibição no São Luiz. Só a título de curiosidade, Aniki Bobó (1942, Manoel de Oliveira) permaneceu apenas três semanas em exibição no Éden.

Se os filmes não permaneceram muito tempo em exibição, porque razão continuam a ser ainda hoje os títulos aparentemente mais populares junto da generalidade do público português? De acordo com um levantamento de dados realizado há uns anos (Cunha 2011), a resposta poderá estar nos anos 60, no período de consolidação da televisão pública portuguesa e da sua programação cinematográfica:

Os resultados dessa pesquisa e consequente análise não comprovam as intenções políticas dos programadores ou dos seus superiores hierárquicos, mas revelam algumas particularidades: a televisão pública ignorou o cinema português produzido nas décadas de 1960 e 1970, tanto o "novo" como o "velho cinema"; a televisão pública recorreu, reconhecidamente, a um repertório de filmes portugueses produzidos até 1954, que emitiu de forma exaustiva e regular; a televisão pública privilegiou de forma clara certos realizadores, nomeadamente alguns dos cineastas mais próximos do poder político e dos mais profícuos da história do cinema português até 1974 . 
Em 1968, o impacto crescente e hegemónico da RTP na sociedade portuguesa era evidente: "o número de aparelhos de televisão registados oficialmente em Portugal era de 305 623. No entanto, a audiência potencial, calculada com base no total da população nacional habitando nas zonas de cobertura da RTP era de cerca de 7 milhões de portugueses (taxa superior a 90\%). Segundo dados da própria RTP, a audiência média diária em 1968 foi de cerca de $1 \mathrm{mi}-$ lhão de telespectadores/dia" (Cádima, 1996, p. 335).

É portanto, com naturalidade, que a televisão pública estabelece ou impõe à generalidade dos espectadores a construção de um determinado cânone de cinema português e de um imaginário social e cultural colectivo (veja-se, por exemplo, a popularidade de expressões como "Ó Evaristo, tens cá disto?" ou "Chapéus há muitos, seu palerma!”). A penetração da programação televisiva parece ter sido determinante na formação e definição do gosto cinematográfico dos telespectadores e dos próprios espectadores de sala e, sobretudo, na construção posterior dos mitos de uma suposta "época de ouro do cinema português", constituída pelas comédias musicais dos anos 30 e 40 do século XX, seguida pelo "divórcio" entre público e cinema português a partir dos anos 50. (Ibidem, 154-155)

A popularidade das comédias à portuguesa foi sendo, portanto, consolidada décadas depois, muito por responsabilidade direta da sua divulgação na televisão pública ao longo das últimas décadas e à disponibilização de cópias em formato caseiro, primeiro em cassetes VHS (anos 80-90) e posteriormente em suporte DVD (séc. XXI), algo que não aconteceu com todo o cinema português. Por exemplo, a criticamente aclamadíssima trilogia transmontana de António Reis e Margarida Cordeiro continua sem qualquer edição em suporte caseiro, assim como as obras de cineastas fundamentais como António Campos, Reinaldo Ferreira, Rino Lupo ou parte significativa da obra de Manoel de Oliveira, só para citar alguns exemplos.

Infelizmente, os mitos continuam a ser construídos no cinema português ainda na atualidade, geralmente norteados por propósitos promocionais e promovidos por diversos lobbies que instrumentalizam e manipulam a história, ignorando ou menosprezando o rigor que a prática historiográfica exige: a proclamação de um segundo "ano zero" no cinema português em 2012 ou a recente consagração de Bárbara Virgínia como a primeira realizadora portuguesa.

Este segundo caso merece particular atenção. De acordo com os seus promotores, o prémio destinado a homenagear uma personalidade feminina portuguesa que se tenha distinguido no cinema recebeu a designação de Bárbara Virgínia (1923-2015) porque ela terá sido a primeira mulher portuguesa a realizar uma longametragem de ficção, deixando "uma obra notável na sétima arte" e foi "a primeira realizadora portuguesa de cinema e a primeira mulher a apresentar um filme no Festival de Cannes, em 1946" (Jervis Communication \& Marketing 2015). 
Ainda que simbólica, a justificação para este batismo está ferida por graves imprecisões. Bárbara Virgínia merece o título de primeira portuguesa a realizar uma longa-metragem de ficção, mas esse mesmo critério tiraria a Aurélio da Paz dos Reis o título de "pai" do cinema português ou aos próprios irmãos Auguste e Louis Lumière a "paternidade" do cinema. Antes de Bárbara Virgínia, pelo menos uma outra portuguesa havia já realizado filmes de curtametragem: entre 1934 e 1937, a açoriana Amélia Borges Rodrigues, entretanto radicada no Brasil, esteve em Portugal para produzir 35 filmes documentais (sendo creditada como realizadora em três deles) sobre várias regiões portuguesas. Quanto ao argumento de que terá sido "a primeira mulher a apresentar um filme no Festival de Cannes”, convém lembrar que nessa primeira edição do Festival de Cannes houve, pelo menos (porque há cerca de dez filmes de realizadores não identificados), mais quatro realizadoras presentes: as inglesas Mary Fields e Jill Craigie, a russa Yelizaveta Svilova e a dinamarquesa Bodil Ipsen. Finalmente, quanto ao argumento da "obra notável”, há outras mulheres que mais se destacaram no contexto cinematográfico português do seu tempo, nomeadamente: a cosmopolita Virgínia de Castro e Almeida (1874-1945), fundadora da Fortuna Films (1922-23), argumentista e produtora de A Sereia de Pedra (1923, Roger Lion), produtora e editora de Os Olhos da Alma (1923, Roger Lion); a já citada Amélia Borges Rodrigues; ou a versátil Beatriz Costa (1907-1996), inquestionavelmente "a mais intensa presença feminina” no cinema português (Costa 1991, 53) e um dos rostos mais internacionais do cinema português.

Servem este breves exemplos para lembrar o imenso trabalho de revisão e reconstrução historiográfica que está por fazer em torno do cinema português. Servem ainda para lembrar Bénard da Costa quando este afirmava, a propósito da história do cinema português, que "os paladares mudem com os tempos e mudem com as vontades" e que isso comprometeu o estudo das histórias do cinema português, geralmente "mal contadas e mal vistas" (Costa 1998, 47).

Em 2008, Tiago Baptista publicou um pertinente ensaio, em forma de álbum fotográfico, onde alertava para a "invenção permanente" de um objeto chamado "cinema português", que deveria dar corpo e sentido identitário aos filmes feitos em Portugal. O título não podia ser mais sugestivo e acertado: A invenção do Cinema Português. Apesar de lembrar que "o passado não é o mesmo para todos", o historiador francês Marc Ferro alerta para as diversas tentativas em uniformizar o passado através de vários aparelhos de reprodução, procurando que uma memória coletiva se imponha como "verdade histórica”. Esta instrumentalização da memória e da história parece orientar-se pela máxima recordada por Marc Ferro - "Controlar o passado ajuda a dominar o presente, a legitimar ascendentes e contestações" - e permite que a história assuma uma dupla função de terapêutica e militância (Ferro [s.d.], 15-17). Ainda a propósito da 
invenção das tradições, Eric Hobsbawn $(1997,9)$ distingue claramente entre "tradição genuína" - a que surge de forma espontânea e se perde no tempo - e "tradição inventada" - que é instituída, de forma insistente e muito rápida, através da repetição simbólica e ritualizada e que obedece a um conjunto de regras reguladas e formalmente institucionalizadas.

Ainda que uma invenção subjetiva, a prática historiográfica necessitava de estar em permanente revisão e problematização, precisa ser atualizada em função de novas fontes e testemunhos que vão sendo recuperados ou valorizados. É necessário e urgente rever as fontes no estudo da história do cinema português, questionando ideias-feitas ou mitos instituídos pela crítica ou por escritos sobre cinema produzidos por autores "comprometidos" com o próprio objeto de estudo. Interessa voltar às fontes, reconstruir o corpus documental e fílmico, rever e reler depoimentos e testemunhos, em suma, fazer um trabalho arqueológico de base, evitando releituras anacrónicas ou comprometidas do passado e procurar olhar o objeto de uma forma inédita, atendendo a diversos fatores contextuais até aqui pouco ou nada considerados.

Felizmente, nos últimos anos, tem sido possível assistir ao desenvolvimento de trabalhos de investigação, individuais (Maria do Carmo Piçarra, Catarina Alves Costa, Paulo Granja, Leonor Areal, entre outros) e coletivos (O trabalho no ecrã: um estudo de memórias e identidades sociais através do cinema PTDC/IVCSOC/3941/2012; Atrás da câmara: práticas de visualidade e mobilidade no filme turístico português EXPL/IVC-ANT/1706/2013, entre outros), que têm trabalhado diretamente com as fontes e têm feito um trabalho de revisão arqueológica, historiográfica e metodológica notável. São trabalhos que, para além do reconhecimento pela comunidade cientifica, aos poucos têm ajudado a consolidar um recente surto editorial que aumenta e diversifica a oferta disponível junto do grande público.

Este dossiê temático reúne quatro ensaios que analisam e refletem sobre diferentes ideias e conceções de Cinema Português que foram sendo esboçadas em ações, textos e filmes ao longo das décadas. O propósito deste dossiê não é responder às perguntas, mas aproveitá-las para rever ideias feitas e também para lançar hipóteses de leitura para problemáticas clássicas e atuais na história do cinema português.

O primeiro ensaio é da autoria de Ana Isabel Soares, e aborda as relações entre cinema e literatura a partir de uma proposta original e desafiante: pode uma certa tendência do cinema português contemporâneo ser um exemplo de um hipotético "cinema literário"? O ensaio propõe um corpus de autores e cineastas que materializam es- 
sa conceção do cinema português como "um país contado através do cinema".

O ensaio seguinte, escrito por Sara Castelo Branco, propõe tratar da complexa relação do cinema português com a temporalidade através de "um conjunto variado de representações do país, que têm em comum o fato de interrogarem simultaneamente o passado e o futuro, a partir do presente", trabalhando, analogamente, a temporalidade e a mitologia nacional.

No seu ensaio, André Rui Graça sugere uma revisitação da problemática do cinema português como "cinema nacional", combinando uma componente historiográfica com análise do discurso e uma vincada vertente de cariz teórico e filosófico, e respondendo a questões relacionadas com as construções ontológicas dos conceitos de cinema nacional, em geral, e de cinema português, em particular.

Finalmente, Iván Villarmea Álvarez é o autor de um ensaio que olha para o cinema português enquanto um "cinema transnacional”, revelando a influência que os efeitos da globalização económica tem provocado na transformação o cinema português contemporâneo, superando a clássica dicotomia entre cinema nacional e cinema estrangeiro.

\section{BIBLIOGRAFIA}

Costa, João Bénard da. 1991. Histórias do Cinema Português. Lisboa: INCM.

Costa, João Bénard da. 1996. O Cinema Português nunca existiu. Lisboa: CTT.

Costa, João Bénard da. 1998. "Breve história mal contada de um cinema mal visto". In Portugal nas Artes, nas Letras e nas Ideias (45-95). Lisboa: Centro Nacional de Cultura.

Cunha, Paulo. 2003. Histórias da História do Cinema Português. Disponível em

https://www.academia.edu/2259615/Hist\%C3\%B3rias_da_H ist\%C3\%B3ria do_Cinema_Portugu\%C3\%AAs_2003.

Cunha, Paulo. 2009. "A exibição de cinema português nas salas lisboetas ma década de 1940". Comunicação apresentada as VIII Jornadas de Maio do grupo Correntes Artísticas e Movimentos Intelectuais do CEIS20. Disponível em https://www.academia.edu/21381980/A_exibi\%C3\%A7\%C3 \%A3o_de_cinema_portugu\%C3\%AAs_nas_salas_lisboetas_m a_d\%C3\%A9cada_de_1940_2009_. 
Cunha, Paulo. 2011. "Emissão de cinema português na televisão pública portuguesa (1957-74)”. In Análise Social, 46, 1, pp. 139156.

Ferro, M. [s.d.]. Falsificações da História. Lisboa: Europa-América.

Hobsbawn, E., Ranger, T. 1997. A invenção das tradições. São Paulo: Paz e Terra.

Jervis Communication \& Marketing (2015). "Academia Portuguesa de cinema atribui Prémio Barbara Virgínia”. Disponível em http://www.jervispereira.pt/Noticias-da-Jervis/NewsletterNovembro-2015/Eventos/Academia-Portuguesa-de-Cinemaatribui-Premio-Barbara-Virginia.

Ribeiro, Manuel Félix. 1983. Filmes, Figuras e Factos da História do Cinema Português 1896-1949. Lisboa: Cinemateca Portuguesa. 